\section{Ulcers in congenital anemia}

\author{
Enzo Fracchia, ${ }^{1}$ Carla Cantello, ${ }^{1}$ \\ Amerigo Gori, ${ }^{1}$ Hugo Partsch, ${ }^{2}$ \\ Gianluca Forni ${ }^{3}$ \\ 'Department of Vascular and \\ Endovascular Surgery, Galliera Hospital, \\ Genova, Italy; ${ }^{2}$ Department of \\ Dermatology and Angiology, Medical \\ University of Vienna, Vienna, Austria; \\ ${ }^{3}$ Department of Thalassemia, Congenital \\ Anemia and Iron Dysmetabolism, Galliera \\ Hospital, Genova, Italy
}

\section{Introduction}

Survival rates in patients with chronic forms of anemia such as sickle cell disease and thalassemia have improved, but the management of comorbidities, such as leg ulcers, remains a challenge. Recalcitrant leg ulcers are a common complication of such conditions and may occur early in life. The incidence of leg ulcers in adults with sickle cell disease is reported to be approximately $30 \%$; ulcers in these patients can last for very long time..$^{-3}$ The pathogenesis of ulcerations in congenital anemia is multifactorial: hypoxia due to anemia, increase of blood viscosity because of bone marrow stimulation, changes in the coagulation and fibrinolytic system, rheological effects, iron overload, venous stasis causing red blood cell diapedesis, followed by extravascular hemoglobin catabolism. The higher intravenous pressure in the upright position acts as a predisposing factor even in the absence of a venous pathology. Among other factors, hemolysis-induced inflammation resulting from greater osmotic fragility of erythrocytes seems to act as a trigger for underlying tissue damage. ${ }^{4}$ Usually classic treatment is directed against all these pathological factors, by general and local means, which is still considered the basic management. However, the results are rather poor. ${ }^{5-9}$ The fact that the localization of the ulcers corresponds exactly to typical venous ulcers suggests an underlying venous pathology. Based on this similarity, several authors have postulated venous incompetence as the deciding underlying lesion, although others have not identified venous flow disturbances in a majority of patients. None of our patients had large varicose veins, and venous reflux or venous obstruction was excluded according to duplex ultrasonography in all cases. ${ }^{10}$ Using the most recent version of clinical severity, etiology, anatomy, pathophysiology classification, these cases can be categorized as $C 6 E c A n P n$, describing active leg ulcers (C6) based on a congenital etiology (Ec) with no anatomical or pathophysiological venous abnormality (An, Pn). ${ }^{11}$ Doppler ultrasound screening for thrombophilia was normal in our patients, the ankle brachial pressure index was greater than 1.0.

Since every type of treatment had been done and these ulcers seemed to be similar in pathology to venous ulcers the author decided to treat these lesions as if they were venous ulcers. We started to treat these patients with inelastic multicomponent bandages. At the beginning the bandage was difficult to apply (Rosydal sys®; Lohmann and Rauscher, Regensdorf, Germany) but many patients lived far away form the hospital and it was necessary to find a single component bandage which was inelastic, cheap and simple applicable by the patients themselves at home. Peha Haft ${ }^{\circledR}$ (Paul Hartmann, Österreich, Austria) was chosen: when properly applied it is able to exert a strong pressure and a strong massaging effect due to its stiffness. Walking exercises were encouraged. Non-adherent, absorbent material was used for local dressings.

\section{Case Series}

Ten patients affected by congenital dyserythropoietic anemia, sikle cell anemia and Thalassemia intermedia with chronic leg ulcers persisting between 12 and 29 years (mean 16 years) without venous out flow disturbances in the lower extremities. Compression therapy was able to heal the ulcers in 5 to 8 months (average 7 months) after several attempts of purely local treatment had failed. Once the ulcers had healed, compression stockings were prescribed to prevent recurrences.

The common denominator in these ten cases was high venous pressure due to gravity. High intravenous pressure caused by sitting and standing without movement is sufficient to trigger chronic inflammation, leading to skin defects on the legs of patients with additional hematological risk factors associated with several microcirculatory abnormalities, as discussed above. Trauma may play an additional role by stimulating the damage of red blood cells. The prolonged average healing time of 7 months in our ten patients points is due to the chronic, recalcitrant nature of the ulcers, which had persisted for several years before compression treatment was initiated. Only compression treatment with short-stretch bandages and walking exercises made the ulcers heal. The therapeutic success of good compression therapy in our cases shows that this treatment is able not only to act against venous reflux but also to counteract gravity in cases with normal valve function. Compression not only reduces edema, it also releases vasoactive enzymes from the
Correspondence: Enzo Fracchia, Department of Vascular and Endovascular Surgery, Galliera Hospital, via Ciro menotti $44-45,3^{\circ}$ piano, Sestri Ponente (GE), Italy.

E-mail: fracchiaenzo@gmail.com

This work is licensed under a Creative Commons Attribution 4.0 License (by-nc 4.0).

CC Copyright E. Fracchia et al., 2016

Licensee PAGEPress, Italy

Veins and Lymphatics 2016; 5:5985

doi:10.4081/vl.2016.5985

endothelial cells, improving microcirculation, reducing inflammation, and promoting lymph drainage. This is especially true for non-yielding, inelastic bandages, which exert a considerable massage effect during walking. ${ }^{12-17}$ These mechanisms may also explain the beneficial effects of compression treatment in patients with other non-venous lesions on the leg, such as vasculitis, cellulitis, and lesions after trauma or surgery.

In conclusion, compression therapy was successful in the treatment of the reported cases and should be considered as a component of treatment strategies for patients with hematological ulcers. In our cases, this simple, inexpensive approach was the winning strategy for resolving a longstanding problem.

\section{References}

1.Trent JT, Kirsner RS. Leg ulcers in sickle cell disease. Adv Skin Wound Care 2004;17:410-6.

2.Josifova D, Gatt G, Aquilina A, et al. Treatment of leg ulcers with plateletderived wound healing factor (PDWHFS) in a patient with beta thalassaemia intermedia. Br J Haematol 2001;112:527-9.

3.Clare A, FitzHenley M, Harris $\mathrm{J}$, et al. Chronic leg ulceration in homozygous sickle cell disease: the role of venous incompetence. Br J Haematol 2002;119: $567-71$.

4.Ackerman Z, Seidenbaum M, Loewenthal E, Rubinow A. Overload of iron in the skin of patients with varicose ulcers. Possible contributing role of iron accumulation in progression of the disease. Arch Dermatol 1988;124:1376-8.

5. Miles MG, Murphy RX Jr. Chronic, nonhealing, lower extremity ulcers responsive to splenectomy in a patient with thalassemia major. Plast Reconstr Surg 2003;112:17345.

6.Velez A, Garcia-Aranda JM, Moreno JC. Hydroxyurea-induced leg ulcers: ismacroerythrocytosis a pathogenic fac- 
tor? J Eur Acad Dermatol Venereol 1999;12:243-4.

7.Pieters RC, Rojer RA, Saleh AW, et al. Molgramostim to treat SS-sickle cell leg ulcers. Lancet 1995;345:528.

8.Steed DL. Clinical evaluation of recombinant human platelet-derived growth factor for the treatment of lower extremity ulcers. Plast Reconstr Surg 2006;117:143S9S.

9.Londahl M, Katzman P, Nilsson A, et al. A prospective study: hyperbaric oxygen therapy in diabetics with chronic foot ulcers. J Wound Care 2006;15:457-9.

10. Billett HH, Patel Y, Rivers SP. Venous insufficiency is not the cause of leg ulcers in sickle cell disease. Am J Hematol 1991;37:133-4.

11. Eklof B, Rutherford RB, Bergan JJ, et al. Revision of the CEAP classification for chronic venous disorders: consensus statement. J Vasc Surg 2004;40:1248-52.

12. Partsch H. Compression therapy: clinical and experimental evidence. AnnVasc Dis 2012;5:416-22.

13. Mosti G, Iabichella ML, Partsch H. Compression therapy in mixed ulcers increase venous output and arterial perfusion. J Vasc Surg 2012;55:122-8.

14. Flour M1, Clark M, Partsch H, et al. Dogmas and controversies in compression therapy: report of an International Compression
Club (ICC) meeting, Brussels, May 2011. Int Wound J 2013;10:516-26.

15. Mosti G, Mattaliano V, Partsch H. Inelastic compression increase venous ejection fraction more than elastic bandages in patients with superficial venous reflux. Phlebology 2008;23;287-94.

16. Partsch $\mathrm{H}$. Improving the venous pumping function in chronic venous insufficiency by compression as dependent on pressure and material. Vasa 1984;13:58-64.

17. Partsch H, Menzinger G, Mostbeck A. Inelastic leg compression is more effective to reduce deep venous refluxes than elastic bandages. Dermatol Surg 1999;25:695700 . 